\title{
Physical exercise effects on the brain during COVID-19 pandemic: links between mental and cardiovascular health
}

\author{
Ricardo Augusto Leoni De Sousa ${ }^{1,2,3}$ - Alex Cleber Improta-Caria ${ }^{4}$ - Roque Aras-Júnior ${ }^{4}$. \\ Edilamar Menezes de Oliveira ${ }^{5}$. Úrsula Paula Reno Soci ${ }^{5} \cdot$ Ricardo Cardoso Cassilhas $^{1,2,3,6}$
}

Received: 27 September 2020 / Accepted: 17 December 2020 / Published online: 25 January 2021

(C) Fondazione Società Italiana di Neurologia 2021

\begin{abstract}
The current pandemic was caused by the severe acute respiratory syndrome coronavirus 2 (SARS-CoV-2). The quarantine period during corona virus disease 19 (COVID-19) outbreak might affect the quality of life leading thousands of individuals to diminish the daily caloric expenditure and mobility, leading to a sedentary behavior and increase the number of health disorders. Exercising is used as a non-pharmacological treatment in many chronic diseases. Here, we review the molecular mechanisms of physical exercise in COVID-19 pandemic on mental health. We also point links between exercise, mental, and cardiovascular health. The infection caused by SARS-CoV-2 affects host cells binding to angiotensin-converting enzyme-2 (ACE2), which is the receptor for SARS-CoV-2. If there is not enough oxygen supply the lungs and other tissues, such as the heart or brain, are affected. SARS-CoV-2 enhances ACE2 leading to inflammation and neuronal death with possible development of mood disorders, such as depression and anxiety. Physical exercise also enhances the ACE2 expression. Conversely, the activation of ACE2/Ang 1-7/Mas axis by physical exercise induces an antiinflammatory and antifibrotic effect. Physical exercise has beneficial effects on mental health enhancing IGF-1, PI3K, BDNF, ERK, and reducing GSK3 $\beta$ levels. In addition, physical exercise enhances the activity of PGC- $1 \alpha /$ FNDC5/Irisin pathway leading to neuronal survival and the maintenance of a good mental health. Thus, SARS-CoV-2 infection leads to elevation of ACE2 levels through pathological mechanisms that lead to neurological and cardiovascular complications, while the physiological response of ACE2 to physical exercise improves cardiovascular and mental health.
\end{abstract}

Keywords Corona virus $\cdot$ Physical activity $\cdot$ Inflammation $\cdot$ Anxiety $\cdot$ Depression $\cdot$ Heart

Ricardo Augusto Leoni De Sousa

ricardoaugustoleonidesousa@gmail.com

1 Multicenter Post Graduation Program in Physiological Sciences (PMPGCF), Brazilian Society of Physiology, Federal University of the Valleys of Jequitinhonha and Mucuri (UFVJM),

Diamantina, Brazil

2 Neuroscience and Exercise Study Group (Grupo de Estudos em Neurociências e Exercício - GENE), UFVJM, Diamantina, Brazil

3 Laboratório de Treinamento Físico (LETFIS), Universidade Federal dos Vales do Jequitinhonha e Mucuri, Rodovia MGT 367, Km 583, Alto da Jacuba, $n^{\circ} 5000$ - CEP, Diamantina, MG 39100-000, Brazil

4 Post-Graduate Program in Medicine and Health, Faculty of Medicine, Federal University of Bahia (UFBA), Salvador, Bahia, Brazil

5 Biodynamics of the Human Body Movement Department, School of Physical Education and Sports, Sao Paulo University - USP, São Paulo, Brazil

6 Post Graduation Program in Health Sciences (PPGCS), UFVJM, Diamantina, MG, Brazil

\section{Introduction}

The current pandemic caused by the novel corona virus, which was named the severe acute respiratory syndrome coronavirus 2 (SARS-CoV-2), started in 2019 in China and being named the corona virus disease 2019 (COVID-19) [1, 2]. The contamination possibly went through a natural selection in an animal host before occurring zoonotic transfer and the COVID-19 affected the world population killing hundreds of thousands until now $[2,3]$. The infection caused by SARSCoV-2 affects host cells through angiotensin-converting enzyme-2 (ACE2), a cellular membrane receptor to the pathogenic coronavirus, and if there is not enough oxygen supply and demand the lungs are affected and these changes will also cause damage to other tissues, such as the heart or brain $[4,5]$.

Due to the features of COVID-19 outbreak many countries have applied social distance or total isolation protocols to their populations, the only effective measure to avoid the contamination of the majority of the people at the same time in order 
to not exceed hospitals capacities, and a minimum of $70 \%$ of social distancing is recommended, $90 \%$ or above is ideal, to control the spread [6]. It is known the importance of understanding the transmission process of SARS-CoV-2 at this moment where people are living in social distancing, but the virus transmission is projected to happen until 2024 and prolonged or intermittent social distance may occur until 2022 what leads to a great change in the lifestyle of the world population $[7,8]$. Thus, it is questionable if being in quarantine, into their own homes, the population would be leaded to develop a sedentary behavior that could contribute to significant physiological changes [9].

The quarantine period during COVID-19 outbreak might affect the quality of life leading thousands of individuals to develop or increase mental health disorders, such as depression or anxiety [2]. Poor eating habits can contribute to cognitive impairment and the development of mood disorders in different animal models [10, 11] and humans [12]. Reduced level of physical activity also contributes to the development of a sedentary behavior during the quarantine what would also favor the development of several chronic diseases, such as mood disorders, obesity, and cardiovascular diseases [13, 14]. It is known that being physically active and exercising are gold healthy standards, and physical exercise is an efficient non-pharmacological approach in many chronic diseases [14-16].

The most common types of physical exercise are aerobic exercise and resistance exercise [17, 18]. Aerobic exercise presents higher consume of oxygen, and predominantly recruits red fibers, also named as type I fibers or fibers of slow contraction $[19,20]$. Conversely, resistance training is characterized by performing exercises against one or multiple external resistance, which could be the individual's body mass or any source of elastic resistance presenting predominantly the recruitment of white fibers, also named as type II fibers or fibers of rapid contraction [19]. It is well stablished that physical exercise reduces the risk of developing cardiovascular diseases, obesity, diabetes, and other chronic diseases and conditions $[14,21]$. It is also known that the regular practice of physical exercise induces beneficial effects in the brain, such as the enhancement in the blood flow to the hippocampus and prefrontal cortex (brain areas related to cognitive functions, memories, and emotions); synapses; neuronal plasticity; neurogenesis; and changes in the morphology of the dendrites [22-24]. Here, we review the molecular mechanisms of physical exercise on mental health during COVID-19 pandemic.

\section{Neurological consequences during the COVID-19 pandemic and potential effects of the physical exercise}

Viral brain invasion may occur through different pathways, such as through infected neurons, entry through the olfactory nerve, infection of the vascular endothelium, or leukocyte migration through crossing the blood-brain barrier [25]. The most common neurological consequences of COVID-19 are anosmia and headache, but other neurophysiological consequences, such as stroke, impaired consciousness, seizure, and encephalopathy, have been reported [25, 26]. A recent study evaluated 214 patients diagnosed with COVID-19, 88 $(41.1 \%)$ were severe and 126 (58.9\%) were non-severe patients, from China and found that $36 \%$ of the total amount had neurological manifestations, including acute cerebrovascular disease and impaired consciousness [26]. More severe patients were likely to have neurologic symptoms than nonsevere patients $(45.5 \%$ vs $30.2 \%)$, such as acute cerebrovascular diseases $(5.7 \%$ vs $0.8 \%$ ), impaired consciousness (14.8\% vs $2.4 \%)$, and skeletal muscle injury (19.3\% vs $4.8 \%)$. The results from this study indicate that COVID-19 severe patients usually present more neurologic disturbances that may occur due to an inflammatory response to the virus.

Brain inflammation has shown to underlie acute and longterm central nervous system damage that might lead to insulin resistance [27], cognitive decline [12], and changes in behavior [28]. The inflammatory response that occurs in acute viral infections may contribute to the development of early mechanisms that underlie the earliest stages of neurodegenerative disorders [29, 30]. COVID-19 has also been associated to memory impairment, psychoses, and posttraumatic stress disorder symptoms due to the induction of neuronal death, synaptic plasticity impairment, and changes in neurotransmitter synthesis [31]. SARS-CoV-2 acts using spike proteins on the viral surface to bind to the ACE2, which act as receptors on human host cells [25]. A growing body of evidence suggests that ACE2 are expressed in multiple regions of the human brain, such as the cortex, striatum and olfactory bulb, and also on many different cell types that make up the central nervous system, including neurons, microglia, astrocytes, and oligodendrocytes $[32,33]$. The activation of ACE2 to SARS-CoV2 infection is the main proposed mechanism to disturb the functioning of central nervous system through the enhancement of an inflammatory response.

\section{Physical exercise and mental health during the pandemic}

There was just one original study found by us about physical exercise during the COVID-19 pandemic that was performed in human individuals until present date [5]. The main results found indicate that a small percentage of individuals (13.8\%) were doing physical exercise during the quarantine period in China and the severity of COVID-19 on life satisfaction depended on physical exercise hours of these individuals. This study was a cross-sectional survey and revealed that people who stopped working and stayed in quarantine reported worse health indicators during the COVID-19 pandemic. 
Controversially, the authors also found that individuals who performed excessive hours of physical exercise during the quarantine period, over $2.5 \mathrm{~h} /$ day, life satisfaction was negatively affected. Another fact to take under consideration is the greater prevalence rates of symptoms of depression and anxiety that naturally raises up due to this social distancing and/or isolation period during the COVID-19 pandemic [34]. These results together indicate that individuals who exercised excessively during the COVID-19 pandemic need to be better observed because they might be more frustrated by the social distancing and isolation. Thus, exercising a lot might not be a signal of good mental health, but a clue about a possible development or establishment of a mood disorder [5]. We can assume that physical exercise has a time-dose dependent effect and too many hours exercising can induce negative health responses, such as the development of mood disorders and overtraining.

COVID-19 pandemic-associated quarantine has taken the population to develop or enhance a sedentary lifestyle, and this can be seen even in teenagers [35]. It is known that the regular practice of physical exercises acts as a modulator of the immune system lowering the incidence, intensity of symptoms, and mortality in viral infections, which can be observed in people who are physically active [36]. The regular practice of sport activity, or physical activity, or physical exercise may represent a complementary therapy to improve mental and social well-being not only during COVID-19 pandemic [2], but also in different conditions, such as in neuromuscular disorders [37].

It has been reported neuroinvasion, neurotropism, and neuroinflammatory mechanisms related to SARS-CoV-2 that will definitely influence and generate many negative mental health outcomes, such as encephalopathy, encephalitis, cerebrovascular pathologies, acute myelitis, and Guillain-Barré syndrome [38]. To investigate the effects of physical exercise on COVID-19 pandemic and how it would contribute to prevent or fight these negative mental health outcomes, using different protocols and types of exercise, making biochemical and molecular analysis is extremely necessary. Unfortunately, there is a lack of original studies to recommend and prescribe what are the best physical exercise protocols to be performed during COVID-19 and their effects in cardiovascular and mental health. The links between exercise, mental, and cardiovascular health should be a part of this investigation too.

The most common mental disorders are depression and anxiety with the prevalence rates varying by age, peaking in the elderly, but also occurring in children, adolescents, and adults [39]. Depression and anxiety might induce a negative effect on several dimensions of quality of life, including being physically active [13]. The pathophysiology of depression and anxiety is not yet fully understood, existing plenty of emerging biomarkers that are suggested to detect the development and the progression of these mental health disorders $[13,40]$.
Nevertheless, physical exercise has been extensively recommended as non-pharmacological approach to reduce the consequences of social distancing/isolation during COVID-19 pandemic [2]. During COVID-19 pandemic, the effects of different physical exercise training are an unexploited field. In this sense, exercising during quarantine should be carefully prescribed and studied.

\section{Physical exercise effects on anxiety and depression}

Anxiety and depression are the most frequently diagnosed neuropsychological disorders [41]. Non-pharmacological and non-conventional interventions, such as physical exercise, are commonly used to treat many people with depression or anxiety [42]. A growing body of scientific evidence indicates that aerobic and resistance training, types of physical exercise, have beneficial effects on physiological and mental health in humans [2, 43, 44] and animal models [24, 45, 46]. Regular physical exercise practice acts on brain health inducing positive changes that can be seen through the enhancement of neurogenesis, angiogenesis, and synaptogenesis, caused by neurotrophins and growth factors, such as the brain-derived neurotrophic factor (BDNF), the insulin-like growth factor 1 (IGF-1), hormones, and second messengers [23, 47]. It has been reported that the regular physical activity is capable to postpone age of occurrence of first-ever stroke and improves long-term outcomes [48], what is extremely important once COVID-19 has higher prevalence and incidence in the elderly.

It has been reported that depressive symptomatology has a significant improvement following a 21 consecutive weeks of swimming and aqua aerobics program or a stretching training program [49]. This study evaluated psychological measures at the beginning and at the end of the protocols. The level of depression was measured by the Geriatric Depression Scale. Resistance training, a type of physical exercise based on weight lifting, has also been reported to be effective on treating mental health issues [50]. Another study showed that even a short-term cycle ergometer training has a significant impact on quality of life, cognition, and depressive symptomatology in multiple sclerosis patients [51]. A recent evaluated the effects of resistance training on the mental health of older patients [52]. The study made at 2 sets of 10 repetitions maximum that consisted of 3 exercises twice a week, lasting for $60 \mathrm{~min}$ each session, for 12 weeks. The resistance training was capable to improve the psychological well-being in the elderly. These results together reveal that aerobic training, resistance training, and even a stretching training program are capable to reduce the levels of depression and its symptomatology.

There is a growing body of evidence saying that a regular physical exercise routine can improve symptoms of anxiety [42]. It is important to remind that sex differences may be seen 
in different pathological conditions, where anxiety normally raises up twice more in females than males individuals [53]. Another situation that can trigger the development of anxiety is having a stressful work or living under pressure at home [28]. A recent study has revealed that aerobic training and Pilates are capable to diminish the levels of anxiety, and depression [13]. The relationship between anxiety and COVID19 pandemic must be investigated in order to develop forms or preventing or treating it.

A recent systematic review and metaanalysis analyzed the existing research works and findings in relation to the prevalence of stress, anxiety, and depression in the general population during the COVID-19 pandemic [54]. The authors used Science Direct, Embase, Scopus, PubMed, Web of Science (ISI), and Google Scholar databases, without a lower time limit and until May 2020, to do their search. The study found a prevalence of stress in 5 studies $(29.6 \%)$ with a total sample size of 9.074 individuals. The authors also reported a prevalence of anxiety in 17 studies (31.9\%) with a sample size of 63.439 individuals, and the prevalence of depression in 14 studies $(33.7 \%)$ with a sample size of 44.531 individuals. These results together show that COVID-19 can lead to the development of psychological disorders and impact the mental health of people in different global areas. Thus, developing strategies that can reduce the impact of COVID-19 on mental health, such as through the regular practice of physical exercise, is necessary.

Another recent study has proposed that physical exercise can be used as a therapy to fight against the mental and physical consequences of COVID-19-associated quarantine, with a special focus on the elderly [2]. The authors comments suggest that outdoor activities are often more available, varied, presenting more facilities, and infrastructures to perform any type of physical exercise. However, there are many possibilities for exercising at home during a quarantine. The WHO has declared the emergency of COVID-19 on January 30, 2020 [55], and due to the impact of this pandemic on social life and mental health, we suggest that doing a bit of physical exercise is better than doing nothing.

Regarding animal studies about the consequences of physical exercise on anxiety and depression, a recent study in mice revealed that amygdala circuity modulates anxiety [56]. Whenever developing an anxious profile there is inhibition of the phosphatidylinositol 3 kinase (PI3K)/protein kinase B (AKT) pathway, which is involved in cell proliferation and survival, and higher activation of the glycogen synthase kinase 3 beta (GSK $3 \beta)$, with the last one being involved in neuronal death [57]. In this context, rats induced to depression by social isolation, decreased the activity of PI3K and AKT, and increased GSK-3 $\beta$ [58]. However, isolated rats that were running on a treadmill induced higher activation of PI3K and AKT with consequent decrease in GSK3 $\beta$, demonstrating that aerobic exercise is beneficial to alleviate the symptoms of depression. Other studies revealed similar results, showing that physical exercise increases the PI3K pathway activity, reduces GSK $3 \beta$, increases neurogenesis and BDNF levels, which seems to be the most sensitive neurotrophin to the effects of physical exercise [23, 59].

Prefrontal cortex and hippocampus have also been reported as important area of the brain to evaluate anxiety through the measurement of BDNF in mice [60-62], while the measurement of the BDNF levels in serum is most commonly used in humans [63]. BDNF is also an immediate upstream regulator of the extracellular signal-regulated kinase (ERK), which has a pivotal role in the pathogenesis, symptomatology, and treatment of the depressive behavior [64]. The inhibition of the ERK pathway in the prefrontal cortex and hippocampus leads to the development of depression. Thus, there are molecular mechanisms that seems to be up or downregulated by physical exercise in anxiety and depression (Fig. 1).

\section{Physical exercise effects on PGC-1a/FNDC5/Irisin pathway}

The regular practice of physical exercise enhances the production and activation of many signaling factors and pathways that contribute to maintain neuronal and cardiac homeostasis, such as the peroxisome proliferator-activated receptor coactivator 1 alpha (PGC-1 $\alpha$ ) pathway $[65,66]$. Physical exercise activates PGC- $1 \alpha$ pathway and is associated with reduced pathological myocardial remodeling, improving blood pressure, decreasing cardiac apoptosis and collagen accumulation, as well as beneficially modulating several genes associated with mitochondrial biogenesis [66]. The activation of PGC$1 \alpha$ pathway also contributed to reducing the myocardial and systemic inflammatory profile by inhibiting the infiltration of macrophages, tumor necrosis factor alpha (TNF $\alpha$ ), and inducible nitric oxide synthase (iNOS), including suppression of chemokines and cytokines in the bloodstream [67].

PGC- $1 \alpha$ leads to the increased expression of fibronectin type III domain-containing 5 (FNDC5), which is cleaved at the $\mathrm{C}$ terminal to favor the release of Irisin [68-70]. Irisin is an exercise-induced myokine identified for its ability to produce the browning of the adipose tissue, to increase energy expenditure, and to inhibit insulin resistance [71]. PGC- $1 \alpha /$ FNDC5/ Irisin modulates peripheral metabolism and stimulates brainderived neurotrophic factor (BDNF) expression in the hippocampus, a key memory center in the human brain $[17,65]$. It was recently reported that Irisin had a positive effect on the expression of several different genes related infection SARSCoV-2 infection in subcutaneous adipocytes cell culture of humans [72]. Until now, there is just this result in vitro about this beneficial effect of Irisin. Here, we suggest that PGC- $1 \alpha /$ FNDC5/Irisin pathway should be investigated due to its 
Fig. 1 Physical exercise regulates the expression of key proteins that might avoid the development of anxiety and depression. Aerobic and resistance physical exercise change muscle fibers characteristics and have beneficial effects on mental health enhancing IGF-1, PI3K, BDNF (serum and brain), ERK, and reducing GSK3 $\beta$ levels. These physiological changes contribute to cell proliferation and survival inhibiting cell death avoiding, consequently, the development of anxiety and depression

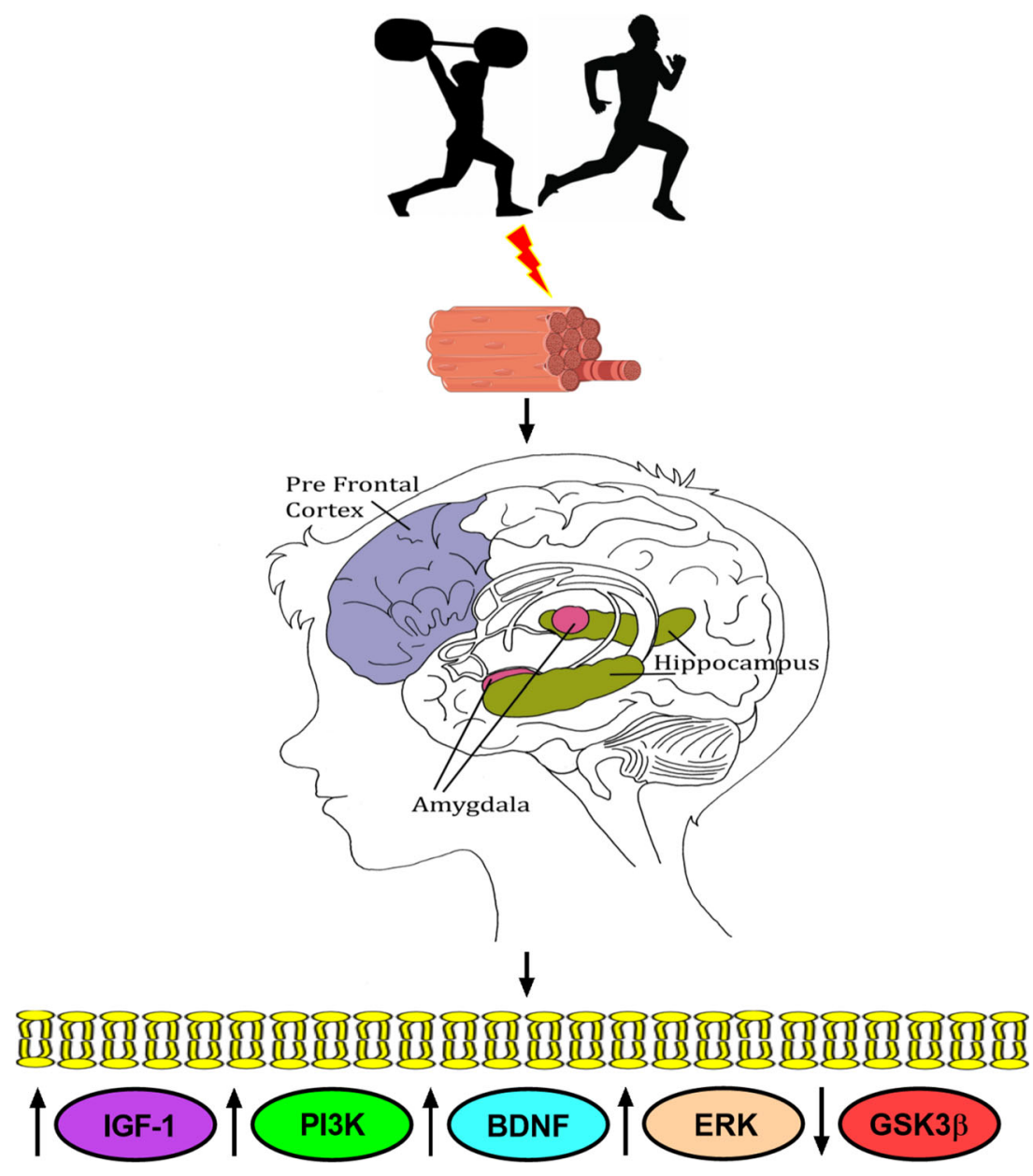

unknown effects on mental health of infected individuals with SARS-CoV-2 (Fig. 2).

Thus, performing physical exercise regularly in quarantine should be investigated into a molecular perspective. Nevertheless, if physical exercise could preserve wellness and mental health in the quarantine is an opened question and similarly if PGC- $1 \alpha /$ FNDC5/Irisin axis could have a determinant role remains to be extensively investigated.

\section{Physical exercise effects on ACE2/Ang 1-7/Mas axis: cardiovascular health mechanisms}

Conversely to what happens in pathological states, the activation of ACE2/Ang 1-7/Mas axis by physical exercise induces an antiinflammatory and antifibrotic effect [73] (Fig. 3). The difference is that ACE2 pathway when activated by physical exercise cleaves angiotensin II (AngII) to angiotensin 1-7 (Ang1-7) production. SARS-CoV-2 entry to pulmonary and others cells binding to ACE2 and disables the positive effect of Ang 1-7 production, inducing an imbalance between Ang II/Ang1-7 ratio and exacerbating inflammatory response [74].
Although ACE2 works as the SARS-CoV-2 receptor, the ACE2/Ang1-7 axis when activated by physical exercise has a protective role to the lungs. A recent study evaluated the associative effects of pharmacological treatment with an ACE2 activator and swimming training for 4 weeks, on the pulmonary lesions induced by bleomycin in rats [75]. The physical training increased functional capacity and reduced tissue fibrosis, type I collagen, transforming growth factor beta-1 (TGF- $\beta-1)$ expression, and beta-prolyl-4-hydroxylase compared to sedentary rats. The authors concluded that exercise training associated with the activation of ACE2 significantly reduces pulmonary fibrosis. In addition, ACE2/Ang1-7 axis has an important role in autonomic control and cardiovascular response. The effect of swimming training on the cardiovascular responses produced by angiotensin peptides at the rostroventrolateral medulla (RVLM) of nonanesthetized normotensive rats [76] shows that the microinjection of Ang-(1-7) in the RVLM induces smaller pressor effect, while Ang II induces higher on trained rats. Thus, exercise training might induce a differential RVLM responsiveness to angiotensin peptides in the autonomic outflow, mainly changing sympathetic drive.

Physiological left ventricular hypertrophy was parallel increased by moderate and high swimming training volume in 
Fig. 2 Physical exercise and SARS-CoV-2 potential effects on the central nervous system. Physical exercise enhances the activity of ACE2 and PGC- $1 \alpha /$ FNDC5/Irisin pathway leading to neuronal survival and the maintenance of a good mental health. SARS-CoV-2 enhances ACE2 activity leading to inflammation and neuronal death with possible development of mood disorders. It is unknown until now what would be the consequences of the regular practice of physical exercise by individuals infected with SARS-CoV-2 on central nervous system

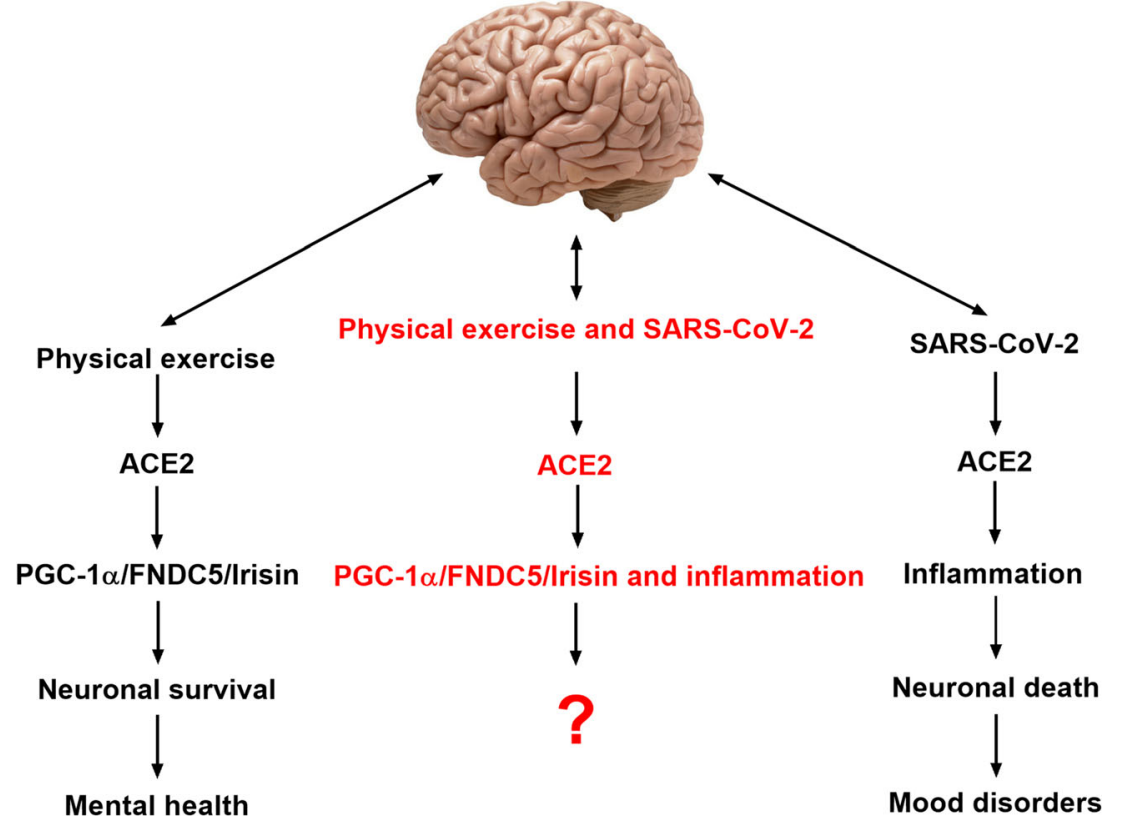

Wistar rats, also increasing ACE2 activity and Ang-(1-7) levels in the heart [77]. This evidence show that ACE2/Ang 1-7 axis is stimulated by physical exercise training. This physiological change improves cardiovascular health, while the stimulation of this axis through pathological mechanisms can lead to cardiovascular complications. Recently, it was showed that physical exercise modulates the ACE2/Ang1-7 axis in active man is dependent on the intensity of the applied protocol [78]. The authors investigated the acute effect of two protocols: high-intensity interval exercise (HIIE) and moderate-intensity continuous exercise (MICE) in plasma and urinary levels of renin angiotensin system components. While the HIIE protocol increased urinary levels of ACE and plasma levels of ACE2, the MICE protocol elevated urinary concentrations of ACE2 and of Ang-(1-7) and decreased plasma level of ACE. Thus, both protocols improved ACE2/ACE ratio. These studies together show convergent evidence that physical exercise acutely increases the activity of ACE2/ Ang1-7 axis, which can be benefic for cardiovascular and global health state. The findings that acute exercise can

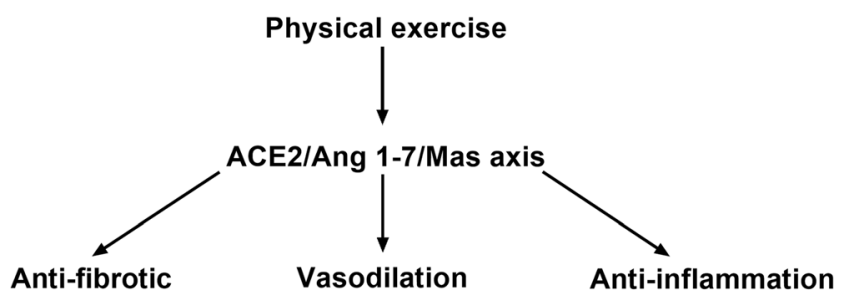

Fig. 3 The main effects of the physical exercise on the ACE2/Ang 1-7/ Mas axis. Physical exercise activates the ACE2 pathway and cleaves AngII to Ang1-7 production leading to physiological changes that are beneficial for the cardiovascular system and inhibiting the inflammatory response, and, consequently, the development of pathological molecular mechanisms modulate plasma and urinary levels of ACE and ACE2 in healthy individuals suggest a protective enzymatic modulation by both protocols. Additionally, when under the physical exercise stimuli ACE2 seems to perform a protective a role in mood disorders as depression and anxiety, which will be reviewed in the next topic.

\section{Physical exercise effects on ACE2 axis: links between cardiovascular and mental health}

Several studies have implicated brain renin angiotensin system in a variety of neurological disorders that affect the memory function, induce depression, and cardiovascular dysfunction [79, 80]. Just like for cardiovascular disease, physical exercise is often a useful non-pharmacological tool to inhibit disturbances on mental health [43] and related negative physiological changes [17]. For many people, social distancing, and quarantine, and in parallel the closure of indoor and outdoor training centers imposes various barriers to maintaining a physically active lifestyle. Concomitantly, psychiatric diseases, such as anxiety and depression, are some of the most prevalent worldwide disturbance and an important public health issue being closely associated with physical inactivity [80]. In this view, in pandemic times it is crucial not confusing social isolation with captivity. The intersection between a trilogy of pandemics: COVID-19, sedentary behavior and mood disorders must be carefully examined, under the risk that one may interact with the other, leading to harmful effects on worldwide public health.

There is evidence that physical exercise effects on ACE2/ Ang1-7 axis can be used as an efficient therapeutic strategy to increase resilience, assist in the development of positive mood 
states, and improve the quality of life [81]. The ACE2/Ang-(17)/Mas pathway, as mentioned, possesses an intrinsically protective role in the central nervous system. On the other hand, the classical pathway (ACE/Ang II) shows an overall proinflammatory and anxiogenic activity in the brain. The activation of PGC- $1 \alpha /$ FNDC5/Irisin pathway through exercise can be seen as a mediator of the ACE2/Ang1-7 axis inducing positive physiological changes (Fig. 4).

In a recent study, physical exercise training provided consistent evidence that depletion of ACE2 reduced brain serotonin and impairs the running-induced neurogenic response [82]. Adult wild type and ACE2-deficient mice daily performed voluntary running and the authors assessed the precursor cells in dentate gyrus of the hippocampus, exploring the effect of exercise stimulus on neurogenesis. The reduction in Ang II degradation in ACE2-deficient mice contributed to the suppression of well stablished running-induced hippocampus cell proliferation. The ACE2 crucial role in the proliferative profile of hippocampus occurs due its interaction with the collectrin domain in neutral amino acid transporter (B0AT1) in the small intestine that increases tryptophan absorption and consequently the serotonin biosynthesis in central nervous system that can activate the neurogenic response. Therefore, lack of ACE2 decreases circulating and brain serotonin levels in mice, and ACE2 is an important modulator in exercisedinduced fast neurogenic response, being a neurogenic target for exercise therapy in pandemic that could prevent and improve mood disorders.

The investigation involving ACE2, SARS-CoV-2 infection and physical exercise is incipient. It remains a broad field to be investigated due the positive effect of regular exercise on mental, neurological, and cardiovascular health. On the other hand, a deleterious effect due sequestration of ACE2 caused to its binding to the SARS-CoV-2 also should be evaluated on further studies. A third question that has not yet been explored is whether increased plasma ACE2 by acute exercise can also increase the predisposition to infection. Then, physical exercise regular practice must be carried out with efficient hygiene and social distancing.

\section{Conclusions}

SARS-CoV-2 infection leads to elevation of ACE2 levels through pathological mechanisms that lead to neurological and cardiovascular complications, while the physiological response of ACE2 to physical exercise improves general health. The main possible molecular mechanisms of the influence of

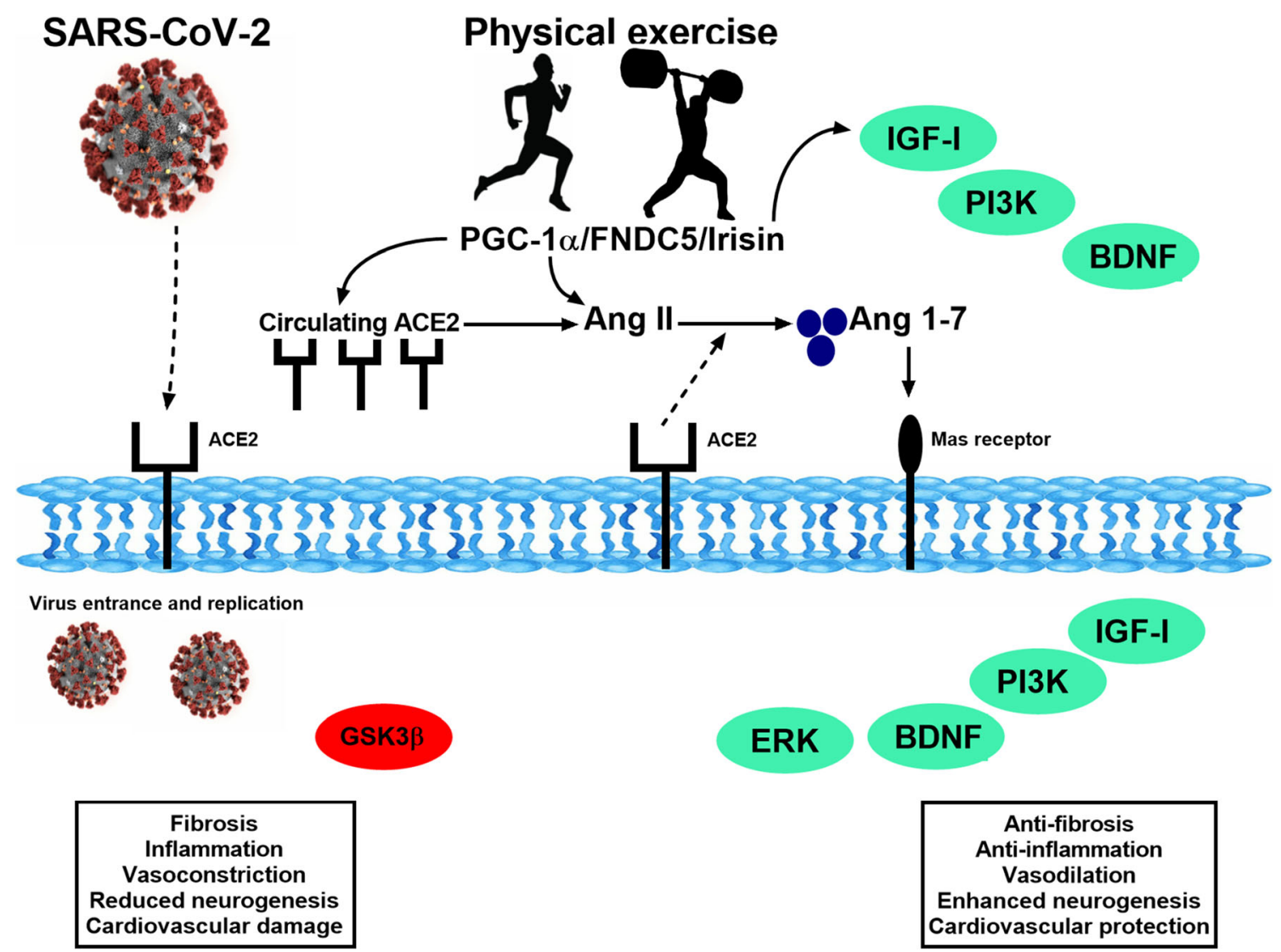

Fig. 4 Molecular mechanisms of physical exercise and SARS-CoV-2. Representative scheme of the main molecular pathways activated by SARS-CoV2 and physical exercise and their respective consequences 
physical exercise on SARS-CoV-2 infection and general health occurs through the activation of PGC- $1 \alpha /$ FNDC5/ Irisin pathway and the ACE2/Ang 1-7 axis.

Authors' contributions RALS, ACIC, EMO, and UPRS review and wrote the manuscript; RALS, ACIC, and UPRS performed the literature search; RALS, ACIC, RAJ, EMO, UPRS, and RCC analyzed and critically discussed the data and reviewed the manuscript; RALS, ACIC, and UPRS designed the review; RALS, ACIC, RAJ, EMO, UPRS, and RCC supervised the review. All authors have read and approved the final version of the manuscript, and agree with the order of presentation of the authors.

Funding RAL Sousa and AC Improta-Caria receive fellowship from Coordenação de Aperfeiçoamento de Pessoal de Nível Superior - Brasil (CAPES) - Finance Code 001. EM Oliveira is supported by National Council for Scientific and Technological Development-CNPq (313479/ 2017-8) and UPR Soci is recipient of fellowship from FAPESP (2015/09919-2).

\section{Declarations}

Informed consent None.

Conflict of interest The authors declare no conflict of interest.

Ethical approval None.

\section{References}

1. Taylor D, Lindsay AC, Halcox JP (2020) Aerosol and surface stability of SARS-CoV-2 as compared with SARS-CoV-1. N Engl J Med:1-3

2. Jiménez-Pavón D, Carbonell-Baeza A, Lavie CJ (2020) Physical exercise as therapy to fight against the mental and physical consequences of COVID-19 quarantine: special focus in older people. Prog Cardiovasc Dis:1-3

3. Andersen KG, Rambaut A, Lipkin WI, Holmes EC, Garry RF (2020) The proximal origin of SARS-CoV-2. Nat Med 26:2-4. https://doi.org/10.1038/s41591-020-0820-9

4. Libby $\mathrm{P}$ (2020) The heart in COVID19: primary target or secondary bystander? JACC Basic Transl Sci 5:1-13. https://doi.org/10.1016/ j.jacbts.2020.04.001

5. Zhang SX, Wang Y, Rauch A, Wei F (2020) Unprecedented disruption of lives and work: health, distress and life satisfaction of working adults in China one month into the COVID-19 outbreak. Psychiatry Res 288:1-7

6. Chang SL, Harding N, Zachreson C et al (2020) Modelling transmission and control of the COVID-19 pandemic in Australia. arXiv:1-24

7. Kissler SM, Tedijanto C, Goldstein E et al (2020) Projecting the transmission dynamics of SARS-CoV-2 through the postpandemic period. Science (80-):1-18

8. Kraemer MUG, Yang C-H, Gutierrez B et al (2020) The effect of human mobility and control measures on the COVID-19 epidemic in China. Science (80-) 4218:1-10

9. Hall G, Laddu DR, Phillips SA, Lavie CJ, Arena R (2020) A tale of two pandemics: how will COVID-19 and global trends in physical inactivity and sedentary behavior affect one another? Prog Cardiovasc Dis:1-3. https://doi.org/10.1016/j.pcad.2020.04.005

10. De Sousa RAL, de Lima EV, da Silva TP et al (2019) Late cognitive consequences of gestational diabetes to the offspring, in a new mouse model. Mol Neurobiol 56:1-11. https://doi.org/10.1007/ s12035-019-1624-0

11. Gao Y, Vidal-Itriago AA, Kalsbeek MJ, Layritz C, García-Cáceres C, Tom RZ, Eichmann TO, Vaz FM, Houtkooper RH, van der Wel N, Verhoeven AJ, Yan J, Kalsbeek A, Eckel RH, Hofmann SM, Yi CX (2017) Lipoprotein lipase maintains microglial innate immunity in obesity. Cell Rep 20:3034-3042. https://doi.org/10.1016/j. celrep.2017.09.008

12. Sousa RAL, Freitas DA, Leite HR (2019) Cross-talk between obesity and central nervous system: role in cognitive function. Interv Obes Diabetes 3:7-9. https://doi.org/10.31031/IOD.2019.03. 000551

13. Vancini RL, Bonal A, Rayes R et al (2017) Pilates and aerobic training improve levels of depression , anxiety and quality of life in overweight and obese individuals. Arq Neuropsiquiatr 75:850 857

14. Pedersen BK, Saltin B (2015) Exercise as medicine - evidence for prescribing exercise as therapy in 26 different chronic diseases. Scand J Med Sci Sports 25:1-72. https://doi.org/10.1111/sms. 12581

15. Laddu DR, Lavie CJ, Phillips SA, Arena R (2020) Physical activity for immunity protection: Inoculating populations with healthy living medicine in preparation for the next pandemic. Prog Cardiovasc Dis 4:6. https://doi.org/10.1016/j.pcad.2020.04.006

16. De Sousa RAL, Hagenbeck KF, Arsa G, Pardono E (2020) Moderate / high resistance exercise is better to reduce blood glucose and blood pressure in middle-aged diabetic subjects. Rev Bras Educ Física e Esporte 34:165-175

17. de Sousa RAL (2018) Brief report of the effects of the aerobic, resistance, and high-intensity interval training in type 2 diabetes mellitus individuals. Int J Diabetes Dev Ctries 38:138-145. https:// doi.org/10.1007/s13410-017-0582-1

18. Soares FHR, de Sousa MBC (2013) Different types of physical activity on inflammatory biomarkers in women with or without metabolic disorders: a systematic review. Women Health 53:298316. https://doi.org/10.1080/03630242.2013.782940

19. Qaisar R, Bhaskaran S, Van Remmen H (2016) Muscle fiber type diversification during exercise and regeneration. Free Radic Biol Med 98:56-67. https://doi.org/10.1016/j.freeradbiomed.2016.03. 025

20. Garber CE, Blissmer B, Deschenes MR, Franklin BA, Lamonte MJ, Lee IM, Nieman DC, Swain DP, American College of Sports Medicine (2011) Quantity and quality of exercise for developing and maintaining cardiorespiratory, musculoskeletal, and neuromotor fitness in apparently healthy adults: guidance for prescribing exercise. Med Sci Sports Exerc 43:1334-1359. https://doi. org/10.1249/MSS.0b013e318213fefb

21. Di Liegro CM, Schiera G, Proia P, Di Liegro I (2020) Physical activity and brain health. Genes (Basel) 10:1-40. https://doi.org/ 10.3389/fphys. 2019.01550

22. Wrann CD, White JP, Salogiannnis J, Laznik-Bogoslavski D, Wu J, Ma D, Lin JD, Greenberg ME, Spiegelman BM (2013) Exercise induces hippocampal BDNF through a PGC- $1 \alpha /$ FNDC5 pathway. Cell Metab 18:649-659. https://doi.org/10.1016/j.cmet.2013.09.008

23. Cassilhas RC, Tufik S, De Mello MT (2016) Physical exercise, neuroplasticity, spatial learning and memory. Cell Mol Life Sci 73:975-983. https://doi.org/10.1007/s00018-015-2102-0

24. De Sousa RAL, Caria ACI, De Jesus Silva FM et al (2020) Highintensity resistance training induces changes in cognitive function, but not in locomotor activity or anxious behavior in rats induced to type 2 diabetes. Physiol Behav 223:1-7. https://doi.org/10.1016/j. physbeh.2020.112998

25. Zubair AS, McAlpine LS, Gardin T et al (2020) Neuropathogenesis and neurologic manifestations of the coronaviruses in the age of coronavirus disease 2019: a review. JAMA Neurol 77:1-10. https://doi.org/10.1001/jamaneurol.2020.2065 
26. Mao L, Wang M, Chen S, He Q, Chang J, Hong C, Zhou Y, Wang D, Miao X, Hu Y, Li Y, Jin H, Hu B (2020) Neurological manifestations of hospitalized patients with COVID-19 in Wuhan, China: A Retrospective Case Series Study. SSRN Electron J. https://doi. org $110.2139 / \mathrm{ssrn} .3544840$

27. de Sousa RAL (2018) Gestational diabetes is associated to the development of brain insulin resistance in the offspring. Int J Diabetes Dev Ctries 39:408-416. https://doi.org/10.1007/s13410-018-0618-1

28. Nieuwenhuys A, Oudejans RRD (2011) Training with anxiety: short-and long-term effects on police officers' shooting behavior under pressure. Cogn Process 12:277-288. https://doi.org/10. 1007/s10339-011-0396-x

29. de Oliveira WK, Cortez-Escalante J, de Oliveira WTGH et al (2016) Increase in reported prevalence of microcephaly in infants born to women living in areas with confirmed Zika virus transmission during the first trimester of pregnancy — Brazil, 2015. MMWR Morb Mortal Wkly Rep 65:242-247. https://doi.org/10. 1016/j.amjhyper.2004.05.007

30. Karwowski MP, Nelson JM, Staples JE, Fischer M, Fleming-Dutra KE, Villanueva J, Powers AM, Mead P, Honein MA, Moore CA, Rasmussen SA (2016) Zika virus disease: a CDC update for pediatric health care providers. Pediatrics 137:e20160621. https://doi. org/10.1542/peds.2016-0621

31. Raony Í, De Figueiredo CS, Pandolfo P et al (2020) Psychoneuroendocrine-immune interactions in COVID-19: potential impacts on mental health. Front Immunol 11:1-15. https://doi.org/10. 3389/fimmu.2020.01170

32. Chen R, Wang K, Yu J et al (2020) The spatial and cell-type distribution of SARS-CoV-2 receptor ACE2 in human and mouse brain. bioRxiv 2020.04.07.030650. https://doi.org/10.1101/2020. 04.07.030650

33. Xia H, Lazartigues E (2008) Angiotensin-converting enzyme 2 in the brain: properties and future directions. J Neurochem 107:14821494. https://doi.org/10.1111/j.1471-4159.2008.05723.x

34. Perlis RH (2020) Exercising heart and head in managing coronavirus disease 2019 in Wuhan. JAMA 3:1-2. https://doi.org/10.1001/ jama.2018.1331

35. Lam K, Lee JH, Cheng P, Ajani Z, Salem MM, Sangha N (2020) Pediatric stroke associated with a sedentary lifestyle during the SARS-CoV-2 (COVID-19) pandemic: a case report on a 17-yearold. Neurol Sci 2:10-12. https://doi.org/10.1007/s10072-02004857-w

36. da Silveira MP, da Silva Fagundes KK, Bizuti MR, Starck É, Rossi RC, de Resende e Silva DT (2019) Physical exercise as a tool to help the immune system against COVID-19: an integrative review of the current literature. Clin Exp Med 2020. https://doi.org/10. 1007/s10238-020-00650-3

37. Vita GL, Stancanelli C, La Foresta S et al (2020) Psychosocial impact of sport activity in neuromuscular disorders. Neurol Sci 41:2561-2567. https://doi.org/10.1007/s10072-020-04345-1

38. Yachou Y, El Idrissi A, Belapasov V, Ait Benali S (2020) Neuroinvasion, neurotropic, and neuroinflammatory events of SARS-CoV-2: understanding the neurological manifestations in COVID-19 patients. Neurol Sci 41:2657-2669. https://doi.org/10. 1007/s10072-020-04575-3

39. World Health Organization (WHO) (2017) Depression and other common mental disorders: Global Health Estimates

40. Strawbridge R, Young AH, Cleare AJ (2017) Neuropsychiatric disease and treatment Dovepress biomarkers for depression: recent insights, current challenges and future prospects. Neuropsychiatr Dis Treat 13:1245-1262. https://doi.org/10.2147/NDT.S114542

41. Wegner M, Helmich I, Machado S, Nardi A, Arias-Carrion O, Budde H (2014) Effects of exercise on anxiety and depression disorders: review of meta-analyses and neurobiological mechanisms. CNS Neurol Disord Targets 13:1002-1014
42. Saeed SA, Cunningham K, Bloch RM (2019) Depression and anxiety disorders: benefits of exercise, yoga, and meditation. Am Fam Physician 99:620-627

43. Cassilhas RC, Antunes HKM, Tufik S, de Mello MT (2010) Mood, anxiety, and serum IGF-1 in elderly men given 24 weeks of high resistance exercise. Percept Mot Skills 110:265-276. https://doi. org/10.2466/pms.110.1.265-276

44. Sousa RAL, Santos J, Hugo-Melo V et al (2014) The changes in lactate levels and body weight during a regional and single triathlon competition in Sergipe, Brazil. Sci Plena 10:1-5

45. Cassilhas RC, Lee KS, Fernandes J, Oliveira MGM, Tufik S, Meeusen R, de Mello MT (2012) Spatial memory is improved by aerobic and resistance exercise through divergent molecular mechanisms. Neuroscience 202:309-317. https://doi.org/10.1016/j. neuroscience.2011.11.029

46. Melo CS, Rocha-Vieira E, Freitas DA, Soares BA, Rocha-Gomes A, Riul TR, Mendonça VA, Lacerda ACR, Camargos ACR, Carvalho LED, de Sousa RAL, Leite HR (2019) A single session of high-intensity interval exercise increases antioxidants defenses in the hippocampus of Wistar rats. Physiol Behav 211:112675. https:// doi.org/10.1016/j.physbeh.2019.112675

47. Oskarsson ME, Paulsson JF, Schultz SW, Ingelsson M, Westermark P, Westermark GT (2015) In vivo seeding and cross-seeding of localized amyloidosis: a molecular link between type 2 diabetes and Alzheimer disease. Am J Pathol 185:834-846. https://doi.org/10.1016/j.ajpath.2014.11.016

48. Morovatdar N, Di Napoli M, Stranges S et al (2020) Regular physical activity postpones age of occurrence of first-ever stroke and improves long-term outcomes. Neurol Sci. https://doi.org/10. 1007/s10072-020-04903-7

49. Albinet CT, Abou-Dest A, André N, Audiffren M (2016) Executive functions improvement following a 5-month aquaerobics program in older adults: role of cardiac vagal control in inhibition performance. Biol Psychol 115:69-77. https://doi.org/10.1016/j. biopsycho.2016.01.010

50. Cassilhas RC, Viana VAR, Grassmann V et al (2007) The impact of resistance exercise on the cognitive function of the elderly. Med Sci Sports Exerc 39:1401-1407. https://doi.org/10.1249/mss. 0b013e318060111f

51. Barry A, Cronin O, Ryan AM, Sweeney B, O'Toole O, Allen AP, Clarke G, O'Halloran KD, Downer EJ (2018) Impact of short-term cycle ergometer training on quality of life, cognition and depressive symptomatology in multiple sclerosis patients: a pilot study. Neurol Sci 39:461-469. https://doi.org/10.1007/s10072-017-3230-0

52. Pedersen MT, Vorup J, Nistrup A, Wikman JM, Alstrøm JM, Melcher PS, Pfister GU, Bangsbo J (2017) Effect of team sports and resistance training on physical function, quality of life, and motivation in older adults. Scand J Med Sci Sports 27:852-864. https://doi.org/10.1111/sms.12823

53. McHenry J, Carrier N, Hull E, Kabbaj M (2014) Sex differences in anxiety and depression: role of testosterone. Front Neuroendocrinol 35:42-57. https://doi.org/10.1016/j.yfrne.2013.09.001

54. Salari N, Hosseinian-Far A, Jalali R, Vaisi-Raygani A, Rasoulpoor S, Mohammadi M, Rasoulpoor S, Khaledi-Paveh B (2020) Prevalence of stress, anxiety, depression among the general population during the COVID-19 pandemic: a systematic review and meta-analysis. Glob Health 16:1-11. https://doi.org/10.1186/ s12992-020-00589-w

55. Erro R, Scannapieco S, Russo M, Picillo M, Barone P (2020) Impact of COVID-19 on neurological patients attending a botulinum toxin service. Neurol Sci:10-12. https://doi.org/10.1007/ s10072-020-04940-2

56. Ahrens S, Wu MV, Furlan A, Hwang GR, Paik R, Li H, Penzo MA, Tollkuhn J, Li B (2018) A central extended amygdala circuit that modulates anxiety. J Neurosci 38:5567-5583. https://doi.org/10. 1523/JNEUROSCI.0705-18.2018 
57. Qiao X, Gai H, Su R, Deji C, Cui J, Lai J, Zhu Y (2018) PI3KAKT-GSK3 $\beta$-CREB signaling pathway regulates anxiety-like behavior in rats following alcohol withdrawal. J Affect Disord 235: 96-104. https://doi.org/10.1016/j.jad.2018.04.039

58. Wang LR, Baek SS (2018) Treadmill exercise activates PI3K/Akt signaling pathway leading to GSK- $3 \beta$ inhibition in the social isolated rat pups. J Exerc Rehabil 14:4-9. https://doi.org/10.12965/jer. 1836054.027

59. De Sousa RAL, Rodrigues CM, Mendes BF et al (2020) Physical exercise protocols in animal models of Alzheimer's disease : a systematic review. Metab Brain Dis 36:1-11. https://doi.org/10. 1007/s11011-020-00633-Z

60. Xiao L, Kish VL, Benders KM, Wu Z-X (2016) Prenatal and early postnatal exposure to cigarette smoke decreases $\mathrm{BDNF} / \mathrm{TrkB}$ signaling and increases abnormal behaviors later in life. Int $\mathrm{J}$ Neuropsychopharmacol 19:1-11. https://doi.org/10.1093/ijnp/pyv117

61. Freitas DA, Rocha-Vieira E, Soares BA, Nonato LF, Fonseca SR, Martins JB, Mendonça VA, Lacerda AC, Massensini AR, Poortamns JR, Meeusen R, Leite HR (2018) High intensity interval training modulates hippocampal oxidative stress, BDNF and inflammatory mediators in rats. Physiol Behav 184:6-11. https:// doi.org/10.1016/j.physbeh.2017.10.027

62. De Sousa RAL, Peixoto MFD, Leite HR et al (2020) Neurological consequences of exercise during prenatal Zika virus exposure to mice pups. Int J Neurosci:1-15. https://doi.org/10.1080/ 00207454.2020.1860970

63. Solati Z, Jazayeri S, Tehrani-doost M et al (2015) Zinc monotherapy increases serum brain- derived neurotrophic factor ( BDNF ) levels and decreases depressive symptoms in overweight or obese subjects : a double-blind. Nutr Neurosci 18:162-168

64. Wang JQ, Mao L (2019) The ERK pathway: molecular mechanisms and treatment of depression. Mol Neurobiol 56:6197-6205. https://doi.org/10.1007/s12035-019-1524-3

65. Lourenco MV, Frozza RL, de Freitas GB et al (2019) Exerciselinked FNDC5/irisin rescues synaptic plasticity and memory defects in Alzheimer's models. Nat Med:165-175. https://doi.org/ 10.1038/s41591-018-0275-4

66. Whitehead N, Gill JF, Brink M, Handschin C (2018) Moderate modulation of cardiac PGC- $1 \alpha$ expression partially affects ageassociated transcriptional remodeling of the heart. Front Physiol 9:1-13. https://doi.org/10.3389/fphys.2018.00242

67. Botta A, Laher I, Beam J, DeCoffe D, Brown K, Halder S, Devlin A, Gibson DL, Ghosh S (2013) Short term exercise induces PGC$1 \alpha$, ameliorates inflammation and increases mitochondrial membrane proteins but fails to increase respiratory enzymes in aging diabetic hearts. PLoS One 8:e70248. https://doi.org/10.1371/ journal.pone. 0070248

68. Oliveira NRC, Marques SO, Luciano TF, Pauli JR, Moura LP, Caperuto E, Pieri BLS, Engelmann J, Scaini G, Streck EL, Lira FS, Pinho RA, Ropelle ER, Silva ASR, de Souza CT (2014) Treadmill training increases SIRT-1 and PGC-1 $\alpha$ protein levels and AMPK phosphorylation in quadriceps of middle-aged rats in an intensity-dependent manner. Mediat Inflamm 2014:1-12. https://doi.org/10.1155/2014/987017

69. Farshbaf MJ, Ghaedi K, Megraw TL (2015) Does PGC1 a / FNDC5 / BDNF elicit the beneficial effects of exercise on neurodegenerative disorders ? NeuroMolecular Med 18:1-15. https://doi.org/10. 1007/s12017-015-8370-x

70. Reza MM, Subramaniyam N, Sim CM, Ge X, Sathiakumar D, McFarlane C, Sharma M, Kambadur R (2017) Irisin is a pro- myogenic factor that induces skeletal muscle hypertrophy and rescues denervation-induced atrophy. Nat Commun 8:1-17. https:/ doi.org/10.1038/s41467-017-01131-0

71. Boström P, Wu J, Jedrychowski MP, Korde A, Ye L, Lo JC, Rasbach KA, Boström EA, Choi JH, Long JZ, Kajimura S, Zingaretti MC, Vind BF, Tu H, Cinti S, Højlund K, Gygi SP, Spiegelman BM (2012) A PGC1a dependent myokine that derives browning of white fat and thermogenesis. Nature 481:463-468. https://doi.org/10.1038/nature10777.A

72. de Oliveira M, De Sibio MT, Mathias LS et al (2020) Irisin modulates genes associated with severe coronavirus disease (COVID-19) outcome in human subcutaneous adipocytes cell culture. Mol Cell Endocrinol 515:1-9. https://doi.org/10.1016/j.mce.2020.110917

73. Nunes-Silva A, Rocha GC, Magalhaes DM, Vaz LN, Salviano de Faria MH, Simoes E Silva AC (2017) Physical exercise and ACE2angiotensin-(1-7)-mas receptor axis of the renin angiotensin system. Protein Pept Lett 24:809-816

74. Vaduganathan M, Vardeny O, Michel T, McMurray JJV, Pfeffer MA, Solomon SD (2020) Renin - angiotensin - aldosterone system inhibitors in patients with covid-19. N Engl J Med 382:1653-1659

75. Prata LO, Rodrigues CR, Martins JM, Vasconcelos PC, Oliveira FMS, Ferreira AJ, Rodrigues-Machado MG, Caliari MV (2017) Original research: ACE2 activator associated with physical exercise potentiates the reduction of pulmonary fibrosis. Exp Biol Med 242: 8-21. https://doi.org/10.1177/1535370216665174

76. Becker LK, Santos RAS, Campagnole-Santos MJ (2005) Cardiovascular effects of angiotensin II and angiotensin-(1-7) at the RVLM of trained normotensive rats. Brain Res 1040:121128. https://doi.org/10.1016/j.brainres.2005.01.085

77. Fernandes T, Soci UPR, Oliveira EM (2011) Eccentric and concentric cardiac hypertrophy induced by exercise training: microRNAs and molecular determinants. Braz J Med Biol Res 44:836-847. https://doi.org/10.1590/S0100-879X2011007500112

78. Magalhães DM, Nunes-Silva A, Rocha GC, Vaz LN, de Faria MHS, Vieira ELM, Rocha NP, Simões e Silva AC (2020) Two protocols of aerobic exercise modulate the counter-regulatory axis of the renin-angiotensin system. Heliyon 6:1-7. https://doi.org/10. 1016/j.heliyon.2020.e03208

79. Phillips MI, De Oliveira EM (2008) Brain renin angiotensin in disease. J Mol Med 86:715-722. https://doi.org/10.1007/s00109008-0331-5

80. Siddiqui F, Lindblad U, Bennet L (2014) Physical inactivity is strongly associated with anxiety and depression in Iraqi immigrants to Sweden: a cross-sectional study. BMC Public Health 14:1-8. https://doi.org/10.1186/1471-2458-14-502

81. de Melo LA, Almeida-Santos AF (2020) Neuropsychiatric properties of the ACE2/Ang-(1-7)/Mas pathway: a brief review. Protein Pept Lett 27:476-483

82. Klempin F, Mosienko V, Matthes S, Villela DC, Todiras M, Penninger JM, Bader M, Santos RAS, Alenina N (2018) Depletion of angiotensin-converting enzyme 2 reduces brain serotonin and impairs the running-induced neurogenic response. Cell Mol Life Sci 75:3625-3634. https://doi.org/10.1007/s00018-0182815-y

Publisher's note Springer Nature remains neutral with regard to jurisdictional claims in published maps and institutional affiliations. 